\title{
Newlands revisited: a display of the periodicity of the chemical elements for chemists
}

\author{
E. G. Marks • J. A. Marks
}

Published online: 17 February 2010

(C) The Author(s) 2010. This article is published with open access at Springerlink.com

\begin{abstract}
This is a periodic table explicitly for chemists rather than physicists. It is derived from Newlands' columns. It solves many problems such as the positions of hydrogen, helium, beryllium, zinc and the lanthanoids but all within a succinct format.
\end{abstract}

Keywords Periodic table $\cdot$ Newlands

\section{The scene}

As a measure of the effort and ingenuity that human beings are prepared to devote to solving puzzles, few can rival that of chemists in their attempts to marry the conflicting demands of presenting the array of chemical elements succinctly and logically with the need to do justice to their physical and chemical properties and relationships (Jensen 1986). ${ }^{1}$ Mazurs (1957) listed 1050 variants while van Spronsen (1969) recorded the history of these developments. Even so, despite these massive endeavours, Emsley (1984) still felt obliged to appeal, through the pages of "New Scientist", to chemists everywhere for a satisfactory solution to this problem. And new suggestions continue to appear (Laing 2005). It is a bold man, therefore, who would venture yet another model.

Part of the challenge is that different disciplines and interests find different varieties of the periodic table better suited to their purpose (Sanderson 1960). Thus, no single table is "best" (Greenwood and Earnshaw 1993) but one would hope for a starting point, a versatile, succinct first table to introduce chemistry as the 'outward manifestation of the

1 Jensen (1986), p. 497: the task has managed to exercise the ingenuity of chemists for more than a century.

Element: macroscopic amounts of a substance composed of atoms of identical atomic number (i.e. isotopes and allotropes are included). See also Paneth (1964) and Lavoisier (1789).

E. G. Marks · J. A. Marks (凹)

Gisborne Hospital, Gisborne, New Zealand

e-mail: totomarks@xtra.co.nz 
properties of the elements' to the intelligent layman and to chemistry students. Confusion has arisen because Mendeleyev, living at a time when physics and chemistry had just begun to meet with Einstein's demonstration of atoms in 1905, used the concept "element" both as meaning 'atom' and as meaning 'simple substance' (Paneth 1964). Physics has annexed the structure of 'atoms' but chemistry still rules 'simple substances'.

\section{The problem}

The current IUPAC model is an 18-group extended version of Mendeleyev's table with the lanthanoids $(Z=57-70)$ and actinoids $(Z=89-102)$ excluded and added on as a subgroup like an afterthought (Rich 2005). There is no prima facie reason why the f-block of chemical elements should be exiled in this way $^{2}$ when the d-block is equally difficult for traditional tables to accommodate, especially the $\mathrm{Fe}, \mathrm{Co}$ and $\mathrm{Ni}$ groups.

The second major difficulty is that the most prominent feature of the periodic table in school education and inorganic chemical reactions is the variation in valency from zero up to eight (Abegg's rule). Traditional popular tables have reflected this by arranging the groups to, by and large, reflect valency. The loss of this in IUPAC's 18-group system is the shortcoming most commonly complained of (James 1985; Scerri 2007) ${ }^{3}$ and which has led to IUPAC's system being virtually ignored by teachers and relegated to a footnote on the history of subcommittees on nomenclature.

Thirdly, the grouping of elements into s, p, d and f "blocks" has now been popular for nearly half a century and is a feature of most school and university texts. The reason for this is that it intelligently reflects electronic structure. However this too is obscured by IUPAC's 1-18 grouping.

Finally, the relationship of Y to La and Lu was finally clarified by Jensen (1982) and seen to be analogous to the relationship of $\mathrm{Mg}$ to $\mathrm{Ca}$ and $\mathrm{Zn}$. This realization reflects the aufspaltung ("splitting") [Sommerfeld] of the energy levels in the sixth period to include the f-electrons and the analogous splitting in the fourth period to include the d-electrons. The first splitting, however, occurred in the second period to accommodate the p-electrons and the relationship of $\mathrm{H}$ to $\mathrm{Li}$ and $\mathrm{F}$ is the corresponding analogue. This is, of course, why $\mathrm{H}$ can reasonably be counted as forming an anomalous alkali metal ion $\left(\mathrm{H}^{+}\right)$or an anomalous halogen gas $\left(\mathrm{H}_{2}\right)$, with corresponding hydride $\left(\mathrm{H}^{-}\right)$as anomalous halide. Unfortunately this observation is nowhere evident in the hapless IUPAC groupings but neither is it clear in traditional tables. Usually hydrogen is placed in IUPAC group 1 with the alkali metals or it floats in an uncomfortable limbo in a space somewhere above the table with many students puzzled by this strange disembodiment from the other elements of the table.

Scerri (1994) has shown the robust experimental basis of the periodic table as the core of chemistry and it behoves chemists to do the periodic table the justice it consequently deserves by interpreting it and representing it as clearly and coherently as possible to gain the maximum information and use from it.

\footnotetext{
2 Jensen (1986), p. 498.

3 James (1985) and Jensen (1986), describes IUPAC's decision as "regrettable"; Scerri E, describes IUPAC's decision as "unfortunate"; etc.
} 


\section{The solution}

The solution of the puzzle ideally demands fidelity to the complex splitting following $\mathrm{H}$, $\mathrm{Mg}$ and $\mathrm{Y}$ while also reflecting, as far as is reasonable, valency variation and electronic structure. It would therefore seem reasonable that any new table should display the valency variation from 0-8 (Abegg's rule) at least of the s-, p- and most of the d-block. The grouping of $\mathrm{Fe}, \mathrm{Co}$ and $\mathrm{Ni}$ seems hardly a matter of great concern as far as valency is concerned because their valency is variable and, anyway, no previous classification of these three groups commands any particular merit.

Groups have previously been labelled IVa or IIb etc. with the 'a's and 'b's being arbitrary. If, instead, the 'a's and 'b's are replaced by $s, \mathrm{p}, \mathrm{d}$ and $\mathrm{f}$, depending upon which subshell is filling, enlightenment is obtained in two ways: group VId ( $\mathrm{Cr}$, Mo, W) immediately tells you (1) the group valency and (2) which block the element is in, i.e. which electron subshell is filling. If the periods are designated by Arabic numerals, then 6VId identifies the element uniquely as $\mathrm{W}$ and indicates its position in the periodic table, its valency and likely physical and chemical properties. This is almost identical to a scheme put forward by Rich (Rich 1965).

One important problem remains: while $\mathrm{Y}=5 \mathrm{IIId}, \mathrm{La}=6 \mathrm{IIIf}$ and $\mathrm{Lu}=6 \mathrm{III}$, what are the corresponding designations of $\mathrm{Mg}, \mathrm{Ca}$ and $\mathrm{Zn}$ ? Even more problematic, what is the designation of $\mathrm{H}, \mathrm{Li}$ and $\mathrm{F}$ ? Zn has a primary valency of two but our reasoning so far would suggest it be designated as $4 \mathrm{Xd}$, i.e. the tenth d-element in the fourth period. Unfortunately this radically violates the principle of reflecting valency. The ' $d$ ' indicates which subshell is filling but the ' $\mathrm{X}$ ' does not indicate the valency, although there should be ten groups in the d-block. So, let the Roman numeral reflect, as far as is reasonable, the valency and do the experiment of seeing what happens: in the fourth period (4-) we have: Sc $=4 \mathrm{IIII}$, $\mathrm{Ti}=4 \mathrm{IVd}, \mathrm{V}=4 \mathrm{Vd}, \mathrm{Cr}=4 \mathrm{VId}, \mathrm{Mn}=4 \mathrm{VIId}, \mathrm{Cu}=4 \mathrm{Id}, \mathrm{Zn}=4 \mathrm{IId}$, with Fe, Co and $\mathrm{Ni}$ variable. It seems sensible and reasonable to call $\mathrm{Fe}$, Co and $\mathrm{Ni}$ the eighth (group VIIId), ninth (group IXd) and tenth (group Xd) groups, respectively, of the d-block. It is sensible because this preserves the valency label where it is relevant and, where it is not (as in $\mathrm{Fe}, \mathrm{Co}$ and $\mathrm{Ni}$ ), it serves to indicate the maximum number of chemical groups in a subshell (ten for the d-block, fourteen for the f-block, etc.), which is reasonable. It is even more reasonable when you consider the tetroxides of 5VIIId and 6VIIId.

In the case of $\mathrm{H}, \mathrm{Li}$ and $\mathrm{F}$ our system would suggest $\mathrm{H}=1 \mathrm{Is}, \mathrm{Li}=2 \mathrm{Is}$ and $\mathrm{F}=2 \mathrm{VIIp}$, respectively. This has several drawbacks. While $\mathrm{H}$ and $\mathrm{Li}$ are in the first group as in IUPAC, the halogens end up in group VII with no suggestion of their joint and symmetrical relationship, with the alkali metals, to $\mathrm{H}$. Just as the fourth, radially quantized, $\mathrm{N}$-shell splits to accommodate the fourth type of azimuthal quantization (f-electrons, so that $\mathrm{Y}=5 \mathrm{IIId}$ yields $\mathrm{La}=6 \mathrm{IIIf}$ and $\mathrm{Lu}=6 \mathrm{IIId})$ and the $\mathrm{M}$-shell splits to accommodate the third type (d-electrons, so that $\mathrm{Mg}=3$ IIs yields $\mathrm{Ca}=4 \mathrm{IIs}$ and $\mathrm{Zn}=4 \mathrm{IId}$ ), so the $\mathrm{L}$-shell splits to accommodate the second type, p-electrons, thus $\mathrm{H}=1 \mathrm{Is}$ yields $\mathrm{Li}=2 \mathrm{Is}$ and $\mathrm{F}=2 \mathrm{Ip}$. The halogens are, thus, group Ip.

Looking at He (1IIs), our system would suggest placing it with Be and, worse, suggest a valency of two. For this reason the first period, prior to any azimuthal splitting, is simply presented as two groups, group $\mathrm{I}(\mathrm{H})$ and group $0(\mathrm{He})$, reflecting valency. A full s-electronic (radial) subshell thus accords with group 0, the noble gases, at least in the first period. We argue that He (1IIs) splits into Be (2IIs) and Ne (2IIp) so that the noble gases become group IIp with the exception of He which is an anomalous first member ${ }^{4}$ of group

${ }^{4}$ Scerri (2007), pp. 275-276. 
IIs. This follows the Janet "left-step" system. ${ }^{5}$ Mazurs's own table ${ }^{6}$ follows Janet, and Bent devotes a whole book (Bent 2006; Gordin 2004) ${ }^{7}$ to supporting it. This seems to us pushing the phenomena of chemistry too far for the sake of the physicists and that the designation of He and group IIp as "group 0" is justified pragmatically. Rich neatly sidesteps the problem by defining group 0 as having outermost subshells filled. ${ }^{8}$

This solution takes advantage of the fact that, in each shell, the s- and p-electrons share the same radial quantum number $(\mathrm{K}, \mathrm{L}, \mathrm{M}, \mathrm{N}, \mathrm{O}, \mathrm{P}$ or $\mathrm{Q})$. Be is the last s-element of the second period but the radially quantized energy levels (first quantum number) in this and succeeding periods are not fully aufgebaut ("built up") [Pauli] until the azimuthally quantized energy levels (second quantum number) are also full. This is $\mathrm{sp}^{3}$ hybridization so, from the second period onwards, it is a full p-subshell (azimuthal) that accords with group 0, the noble gases. The alkaline earth metals $\mathrm{Be}, \mathrm{Mg}, \mathrm{Ca}, \mathrm{Sr}, \mathrm{Ba}$ and $\mathrm{Ra}$ are thus designated group IIs. B, C, N, and $\mathrm{O}$ are then in groups IIIp, IVp, Vp and VIp, respectively. VIp also reflects the maximum number of p-electrons.

$\mathrm{Ne}$ is clearly group 0 so that a full azimuthal subshell is designated group 0 . As before, the maximum chemical group number in a subshell corresponds to the total number of electrons in the new subshell (six in the case of the p-subshell) and, when under eight, to the valency (Abegg again). Bayley (1882) constructed just such a table which is faithful to these considerations but which lacked the modern rational labelling and explanation of the groups that were unknown in Bayley's time.

Popularized by Thomsen (1895) and Bohr (1923), Bayley's table is excellent but suffers from its inconvenient length as does even the most popular long table, that of Werner (1905). Further, the valency groups are diagonally disposed in Bayley whereas they are in the clearest, columnar form in Werner. The current IUPAC table is actually a surgically resected form of Werner's table with the dissected f-groups laid out below, like a pathology specimen. Even these still vary between La and Lu, in group IIId. The main disadvantage of these two long forms is that either the groups are not columnar (as in Bayley) or they need to be repeated (as in Werner and IUPAC) for the d- and f- blocs, e.g. carbon, titanium and cerium (all group IV) are in three separate columns. However, all current tables need the groups repeated for the s-bloc because the splitting of the first period is never explicitly acknowledged.

Mendeleyev's table used to be the most popular of the short forms, with the p- and d-groups in the same columns (excepting VIIId, IXd and Xd), but diagonally shifted. Earlier forms often included the first four f-groups as well: IIIf ( $\mathrm{La}$ and Ac), IVf (Ce and $\mathrm{Th}$ ), Vf (Pr and $\mathrm{Pa}$ ) and VIf (Nd and $\mathrm{U})$.

The original periodicity of the chemical elements' properties was first clearly noted in the p-block and the s-block excluding the first period. Most tables since have preserved this as a requirement of chemical intelligibility but the unperceived paradox right at the beginning of the table remained. Thus most tables have two columns for group I (the alkali metals and the halogens) and group II is repeated as a separate group 0 . These distinctions are chemically valid but need not be at the expense of duplicating columns. The columns

\footnotetext{
5 Mazurs (1974), Fig. 103, p. 93; Bent (2006) calls them "Left-Step Periodic Tables" (LSPTs).

${ }^{6}$ Mazurs (1974), Fig. 136, p. 134.

7 Even Bent concedes (p. 116) his "LSPT is not a chemical table". Nevertheless, our table accommodates Bent's concerns about He and Be. Bent quotes Mendeleyev frequently in support of his view that the demands of physics are paramount in constructing periodic tables. Bent's partial use of Mendeleyev is not borne out by Gordin's biography of Mendeleyev.

8 Rich (1965), p. 1.
} 


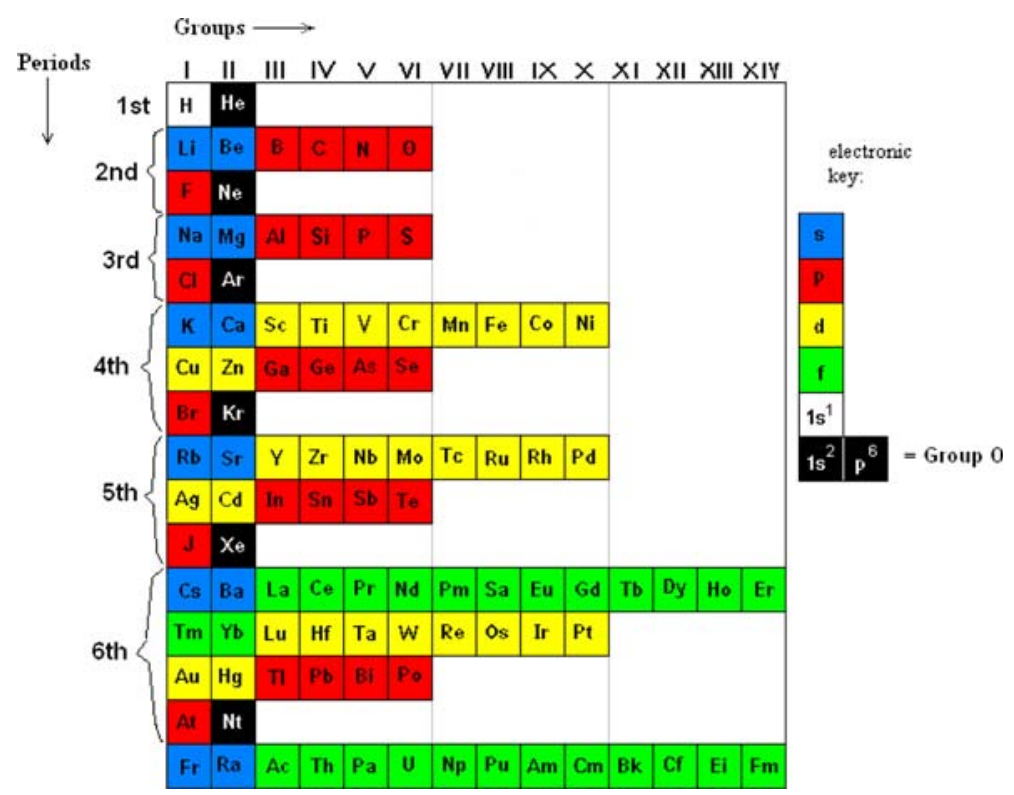

Fig. 1 Marks Brothers' periodic table (2010)

under $\mathrm{H}$ and $\mathrm{He}$ yield their chemically contrasting groups quite naturally in our table. Under H the shell 'splits'; under He azimuthal hybridization is the cause. Considering the first hundred elements (Cameron 2003; Moody 2006), ${ }^{9}$ our table is 16 rows $\times 14$ columns. It preserves the relationships demonstrated in Bayley (1882) but it is more compact in form and the groups are vertical columns. Our table remedies what Sanderson (Sanderson 1960) called "serious faults" of current tables and satisfies Jensen's (1986) three criteria (Jensen 1986): it is 2D rather than 3D; "medium" rather than "long"; and it is a chemical table rather than a table of electronic configurations: Marks Bros PT, 2010 (Fig. 1).

As a mnemonic, the halogens and the rest of the p-bloc are red and the alkali metals and the alkaline earth metals are blue (cf. Litmus). The d-bloc is a bright sunshine yellow reflecting the variety of colours in their salts (as do their names, such as chromium and iridium). The f-bloc is green, suggesting comparison with the subtle variety of greens seen in nature and the gentle gradation of properties found in these elements. $\mathrm{H}$ is white, from which all these colours emerge. The noble gases are black. ${ }^{10}$ This colour scheme we would recommend for the blocs whatever table is used.

In summary, the f-block emerges in the middle of the table as Y yields La and Lu; the d-block similarly emerges as $\mathrm{Mg}$ yields $\mathrm{Ca}$ and $\mathrm{Zn}$, and the p-block emerges as $\mathrm{H}$ yields $\mathrm{Li}$ and F. Should Be, Mg, etc. be group IIp with B, C, N and O as IIIp, IVp, Vp and VIp, respectively? And, with the halogens as group Ip, should the noble gases be group IIs? As we know, this is not the case: Ne occurs with the sixth p-electron and Be (2IIs) is not a noble gas like He because of azimuthal hybridization. This makes it difficult to place the

\footnotetext{
9 In naturally occurring systems such as stars, neutron capture builds up elements as far as $Z=100$. Although Fm-257 has a half-life of a few months, this process can go no further. (Cameron 2003). This is the reason our table ends at fermium. It appears to be the end of the "natural" elements found in the Universe (Moody 2006).

${ }^{10}$ Since their chemical properties seem to disappear down a "black hole"!.
} 
noble gases in group II without doing violence to all the didactic principles for which chemists invented the periodic table. ${ }^{11}$ This is why, in almost all tables, this group is out on its own: in going from $\mathrm{He}$ to $\mathrm{Ne}$, the chemical properties do not follow simply from the electronic structure. ${ }^{12}$ We have followed the principle of placing the noble gases in a group IIp but, in practice, for reasons of pedagogy and phenomenal chemistry, have named it, together with He, group 0 with its own colour, black.

Clearly, the rule for noble gas formation is not a full s-shell. Empirical chemistry shows that the first period ends with a noble gas at $Z=2$, a full s-shell. But the next noble gas occurs at $Z=10$, a full $\mathrm{p}$-shell. Perhaps the rule is that a noble gas occurs at the end of the subshell added in that period, i.e. when the newest subshell is filled. Unfortunately this would demand noble gases at $Z=30$ (zinc) and $Z=70$ (ytterbium). Perhaps then it is the case only if the newest subshell is outermost. ${ }^{13}$ Since this is not true of the $\mathrm{d}$ - and f-electrons, it would explain why $\mathrm{Zn}$ and $\mathrm{Yb}$ are not noble gases. But what about Pd? ${ }^{14}$

\section{Subgroups}

From Gmelin's first table of 1843 to Mendeleyev's of 1869, chemists repeatedly noted relationships, by grouping, of carbon and silicon with titanium and zirconium; of chromium, molybdenum and tungsten with uranium; of calcium and strontium with zinc and cadmium; of tin with cerium and thorium, etc. Even the alkali metals (lithium, sodium, potassium, etc.) and the contrasting noble metals (copper, silver and gold) share a valency of $+1{ }^{15}$ These relationships are not accidental but reflect the common chemical action of valency throughout the s, p, d and f subgroups. IUPAC's 1-18 scheme of column labels does not acknowledge the existence of secondary chemical kinships ${ }^{16}$ but this is immediately apparent from our table, with colour distinguishing the subgroups. Our table is essentially a set of Newlands' columns (Newlands 1865) with secondary kinships segregated into subgroups by colour.

Bent's ${ }^{17}$ strident championship of physics (especially electronic structure derived from spectroscopy) as arbiter of periodic tables is comprehensively countered by Scerri's ${ }^{18}$ demonstration of the imperatives of chemistry. From the beginnings of the application of atomic physics to the periodic table, physicists have had to accommodate their fertile imaginations to the realities of chemistry: from Thompson's and Bohr's first attempts

\footnotetext{
11 Greenwood and Earnshaw (1993), p. 25: "It should always be remembered, however, that it is incorrect to 'deduce' known chemical phenomena from theoretical models; the proper relationship is that currently accepted theoretical models interpret the facts..." A recent version of this question was asked by a schoolboy: "Why is beryllium not considered a noble gas?" (www.madsci.org/posts/archives/200104/988047875.Ch.r.html) and elicited the following response from J Christie of the chemistry department of La Trobe University, Victoria, Australia (22/4/01): "It is chemical properties and behaviour that determine the shape of the periodic table, and electronic structure that explains and rationalizes it, not the other way around".

12 Sanderson (1960), p. 8 writes "No complete, theoretical basis for determining exactly how the electrons are distributed in any given atom is known".

13 Rich (1965), p. 1.

14 Sanderson (1960), p. 11.

15 Paneth (1964), p. 49.

16 Bent (2006), p. 71.

17 Bent (2006), e.g. \$75, p. 65.

18 Scerri (2007) especially Chaps. 6-9.
} 
(Scerri 1997) to derive electronic structures, the intuition of chemists such as Bury and Mainsmith have had to return the physicists to the fold. Any number of arcane analyses involving statistical comparisons, set theory, group theory, matrices and symmetries (Rouvray and King 2004) now make the periodic table a playground for mathematicians. Good luck to them, but their reflections are likely to be even further removed than those of physicists from a chemist's primary interest. The geologists, metallurgists and others have not presumed to claim their tables as 'better' than the chemists: they have simply adapted the chemists' periodic table to their own purposes. Physicists have no greater claim, even though they study the electronic structure of atoms ${ }^{19}$ : what is offered here is a basic periodic table for chemists, who study the behavior and interactions of types of matter viz. the elements ${ }^{20}$ and their compounds.

Our table suggests a more logical ordering of the chapters of texts on the elements, viz:

$\S 1$. Group I: hydrogen $(\mathrm{H})$;

Is the alkali metals ( $\mathrm{Li}, \mathrm{Na}, \mathrm{K}, \mathrm{Rb}, \mathrm{Cs}, \mathrm{Fr}$ );

Ip the halogens ( $\mathrm{F}, \mathrm{Cl}, \mathrm{Br}, \mathrm{J}, \mathrm{At})$;

Id the noble metals $(\mathrm{Cu}, \mathrm{Ag}, \mathrm{Au})$; If ( $\mathrm{Tm}, \mathrm{Mv})$.

§2. Group II: the noble gases (He + IIp), alternately Group 0 ( $\mathrm{He}, \mathrm{Ne}, \mathrm{Ar}, \mathrm{Kr}, \mathrm{Xe}, \mathrm{Nt})$;

IIs the alkaline earth metals $(\mathrm{Be}, \mathrm{Mg}, \mathrm{Ca}, \mathrm{Sr}, \mathrm{Ba}, \mathrm{Ra})$;

IId the galvanic metals ( $\mathrm{Zn}, \mathrm{Cd}, \mathrm{Hg}$ ); IIf ( $\mathrm{Yb}, \mathrm{No}$ ).

§3. Group III: IIIp (B, Al, Ga, In, Tl); IIId (Sc, Y, Lu); IIIf (La, Ac).

§4. Group IV: IVp (C, Si, Ge, Sn, Pb); IVd (Ti, Zr, Hf); IVf (Ce, Th).

§5. Group V: Vp (N, P, As, Sb, Bi); Vd (V, Nb, Ta); Vf (Pr, Pa).

§6. Group VI: VIp the chalcogens (O, S, Se, Te, Po); VId (Cr, Mo, W); VIf (Nd, U).

§7. Group VII: VIId (Mn, Tc, Re); VIIf (Pm, Np).

§. Group VIII: VIIId (Fe, Ru, Os); VIIIf ( $\mathrm{Sm}, \mathrm{Pu})$.

§. Group IX: IXd (Co, Rh, Ir); IXf (Eu, Am).

$\S 10$. Group X: Xd (Ni, Pd, Pt); Xf (Gd, Cm).

$\S 11$. Group XI: XIf (Tb, Bk).

§12. Group XII: XIIf (Dy, Cf).

§13. Group XIII: XIIIf (Ho, Ei).

§14. Group XIV: XIVf (Er, Fm).

To make it clear that this is a chemical table of the behaviour of elements ("simple substances") (Paneth 1964; Lavoisier 1789), not a physical table of electronic structures, the subgroups may be better called b (blue), $\mathrm{r}$ (red), y (yellow) and $\mathrm{g}$ (green) for $\mathrm{s}, \mathrm{p}, \mathrm{d}$ and $\mathrm{f}$, respectively, or even following an earlier fashion, A, B, C and D.

\section{What is the heuristic value of our new table?}

$\mathrm{H}$ should give rise in its 'daughter groups' Is and Ip, to a group with one s-electron more than a completed period (the alkali metals, group Is) and to a group with one p-electron less than a completed period (the halogens, group Ip). This is, indeed, found to be the case. Mg,

\footnotetext{
19 Yet they still cannot derive Madelung's rule (Bent 2006, p. 66).

${ }^{20}$ Element: macroscopic amounts of a substance composed of atoms of identical atomic number (i.e. isotopes and allotropes are included). See also (Paneth 1964; Lavoisier 1789).
} 
similarly, in its daughter groups, gives rise to the alkaline earth metals, group IIs ( $\mathrm{Ca}, \mathrm{Sr}$, $\mathrm{Ba}, \mathrm{Ra})$ and the galvanic metals, group IId $(\mathrm{Zn}, \mathrm{Cd}, \mathrm{Hg})$. In like manner, Y gives rise to the first of the inner transition groups (La and Ac: group IIIf) and to the transition metals Lu and Lw of group IIId. These are also observed phenomena. The system creates groups such as IVf (Ce and Th) and VIId (Mn, Tc, Re) with valencies of four and seven, respectively for these groups. Again, this is a well-known feature of these elements' chemistries.

If it has any validity, our table should be predictive. Besides groups such as Is ( $\mathrm{Li}, \mathrm{Na}$, $\mathrm{K}, \mathrm{Rb}, \mathrm{Cs}, \mathrm{Fr})$, Ip (F, Cl, Br, J, At) and $\mathrm{Id}(\mathrm{Cu}, \mathrm{Ag}, \mathrm{Au})$, it creates group If (Tm and $\mathrm{Mv}$ ). Similarly it creates a group IIf ( $\mathrm{Yb}$ and No). ${ }^{21}$ Therefore we make this prediction: Hypothesis: There exists $\mathrm{Tm}+1$ and $\mathrm{Mv}+1$. $\mathrm{Yb}+2$ and $\mathrm{No}+2$ are in fact observed. Recent research has reported Mv (ekathulium) +1 (Mikheev et al. 2004) but not Tm +1 yet.

\section{A note on nomenclature}

Beyond $Z=100$, there seems little reason to be concerned about arguments over nomenclature since these elements $(Z>100)$ appear unlikely ever to have any practical relevance for chemistry (Cameron 2003; Moody 2006). Hence our table here ends at $\mathrm{Z}=100$.

A standard text (Pimentel and Spratley 1971) saw fit to write: "Lanthanum has only one important oxidation state in aqueous solution, the +3 state. With few exceptions, this tells the whole boring story about the other lanthanides". Jensen wrote similarly, explaining it was a consequence of the current convention. ${ }^{22}$ Undoubtedly ugly names, like dysprosium and neodymium, and confusing ones, like terbium, ytterbium and erbium, aggravate this. The problem is not confined to the lanthanides, with unimaginative examples like technetium, protoactinium and astatine.

In the case of $Z=86$, Ramsay gave it the name 'niton' (Latin nitens $=$ shining) on account of its spontaneous luminescence. 'Radon' is short for 'radium emanation', Nt-222, and is thus merely an isotope of niton. Similarly thoron is Nt-220 and actinon is Nt-219. We do not refer to hydrogen as 'protium'. 23

Acknowledgments We acknowledge the inspiration of our grandfather, Arthur Hodgkinson Marks (18821960), erstwhile chemical engineer and professor of metallurgy, whose laboratory kindled our boyhood interest in chemistry; to O Sachs for "Uncle Tungsten" (Picador, London 2001) whose boyhood so mimicked our own; to the encouragement of Professor E Scerri and to two referees who directed us to the writings of Rich and Sanderson. This periodic table is dedicated to the memory of our late father Edward Newton Marks (1919-2009).

\footnotetext{
21 Bassett (1892) placed Tm and $\mathrm{Yb}$ in groups I and II, below Rb and Sr, respectively. (Mazurs 1974, Fig. 84, p. 77). Mazurs (1974) puts Tm and Yb in groups I and II, respectively, in his own 1955 table (Fig. 105, p. 95). Laing (2005) follows this idea but divides the f-bloc into two sets of seven, rather as one might divide the d-bloc into two sets of five. He also duplicates the whole of the p-bloc to demonstrate its subgroup relations. From his picture of Mendeleyev's grave (Laing 2005; Figs. 12, 13) it seems the Russians would be happy with thulium in group If. There Tm ends up in Group I which Laing criticizes even though ekathulium $(\mathrm{Mv}+1)$ has been observed. Bent (2006), p. 78, uses a comparison between $\mathrm{Cu}$ and Tm plus that between $\mathrm{Zn}$ and $\mathrm{Yb}$ in a calculation of the boiling point of $\mathrm{He}$.

22 Jensen (1986), p. 498.

23 Lavoisier (1789), preface $\$ 17$.
} 
Open Access This article is distributed under the terms of the Creative Commons Attribution Noncommercial License which permits any noncommercial use, distribution, and reproduction in any medium, provided the original author(s) and source are credited.

\section{References}

Bayley, T.: On the connexion between the atomic weight and the chemical and physical properties of elements. Philos. Mag. 13, 26-37 (1882)

Bent, H.: New ideas in chemistry from fresh energy for the periodic law. Author House, Bloomington, IN (2006)

Bohr, N.: The structure of the atom. Nature 112, 29-44 (1923)

Cameron, A.G.W.: Some nucleosynthesis effects associated with r-process jets. Astrophys. J. 587, 327-340 (2003)

Emsley, J.: A periodic problem. New Sci. 101, 38 (1984). No. 1392, 12th January

Gordin, M.D.: A well-ordered thing. Basic Books, New York (2004)

Greenwood, N.N., Earnshaw, A.: Chemistry of the elements, p. 24. Pergamon, Oxford (1993)

James, M.H.: Chemical elements. New Sci. 105, 49 (1985). No. 1449, 28th March

Jensen, W.B.: The positions of lanthanum (actinium) and lutetium (lawrencium) in the periodic table. J. Chem. Ed. 59, 634-636 (1982)

Jensen, W.B.: Classification, symmetry and the periodic table. Comput. Math. Appl. 12B, 487-510 (1986)

Laing, M.: A revised periodic table with the lanthanides repositioned. Found. Chem. 7, 203-233 (2005)

Lavoisier, A.L.: Traité elémentaire de chimie. Cuchet, Paris (1789). (Trans. R Kerr, Encyclopaedia Britannica, Chicago 1988) preface $\$ 16$

Mazurs, E.G.: Graphic representations of the periodic system during 100 years, 2nd edn. Alabama UP, Alabama 1957 (1974)

Mikheev, N.B., et al.: Lower oxidation states of f elements. Radiochemistry 46, 297-311 (2004)

Moody, K.: Ask the expert: what is the difference between artificial and natural elements?" NOVA Sci. Now (2006): www.pbs.org/wgbh/nova/sciencenow/3313/02-ask.html)

Newlands, J.A.R.: On the law of octaves. Chem. News 12, 83 (1865)

Paneth, F.A.: Chemistry and beyond. Interscience, New York (1964). Chapter 6

Pimentel, G., Spratley, R.: Understanding chemistry, p. 862. Holden-Day, San Francisco (1971)

Rich, R.L.: Periodic correlations. Benjamin, New York (1965). pp. 4, 5

Rich, R.L.: Are some elements more equal than others? J. Chem. Ed. 82, 1761-1763 (2005)

Rouvray, D.H., King, R.B.: The mathematics of the periodic table. Nova, New York (2004)

Sanderson, R.T.: Chemical periodicity, p. 13. Reinhold, New York (1960)

Scerri, E.R.: Plus ça change. Chem. Britain. 379-381 (1994)

Scerri, E.: Has the periodic table been successfully axiomatized? Erkenntnis 47, 229-243 (1997)

Scerri, E.: The periodic table: its story and its significance, p. 14. OUP, Oxford (2007)

Thomsen, J.: Systematische Gruppierung der chemischen elemente. Z Anorg. Chem. 9, 190-193 (1895)

van Spronsen, J.W.: The periodic system of the chemical elements: a history of the first 100 years. Elsevier, Amsterdam (1969)

Werner, A.: Beitrag zum Aufbau des periodischen systems. Ber deut chem. Ges. 38, 914-921 (1905) 